\title{
OVER TABAK.
}

De schatkist van het vereenigd koningrijk van Groot-Brittanje en Ierland geniet, door eene belasting op het verbruik van tabak, een jaarlijksch inkomen van ruim $f 52.000 .000-$ of nagenoeg $f 2$ per hoofd der bevolking.

Deze aanmerkelijke opbrengst wordt niet verkregen zonder zware regten, tegenwoordig bedragende:

Regten op den invoer tot verbruik.

sh. $d$.

Voor onbewerkte tabak . . $f 4.20$ per kilo (3. $1^{k / s}$ per Eng. \&) Bewerkte tabak en sigaren . $12.60 "$ " $(9.52 / 5 "$ " ") Snuif . . . . . . . . " $8.40 "$ " $\left.6.3^{5 / 5} n " n\right)$

De volgende staat vermeldt het bedrag der invoeren van tabak over de jaren 1849 en 1850 , en de hoeveelheden welke daarvan zijn angegeven tot inlandsch verbruik:

\begin{tabular}{|c|c|c|c|c|}
\hline \multirow{3}{*}{$\begin{array}{l}\text { Onbewerkte tabak . } \cdot \text { - } \\
\text { Bewerkte tabak en sigaren }\end{array}$} & Totale invoer. & $\begin{array}{l}49 . \\
\text { Aangegeven tot } \\
\text { verbruik en met } \\
\text { bel. bez waard. }\end{array}$ & Totale invoer. & $\begin{array}{l}50 \text {. } \\
\text { Angegeven tot } \\
\text { verbruik en noct } \\
\text { bel. bezwaard. }\end{array}$ \\
\hline & $\begin{array}{l}\text { Eng. R. } \\
42.098 .126\end{array}$ & $\begin{array}{l}\text { Eng. 1t. } \\
\mathbf{2 7 . 3 4 8 . 4 1 9}\end{array}$ & $\begin{array}{l}\text { Eng. } \mathbb{R} \text {. } \\
35.661 .358\end{array}$ & $\begin{array}{l}\text { Eng. } 16 . \\
27.387 .960\end{array}$ \\
\hline & 1.912 .315 & 204.539 & 1.566 .321 & 195.982 \\
\hline nuif . & 1.139 & 280 & 1.197 & 464 \\
\hline & $\mathrm{ng}$ & 27.553 & Eng. & 27.584 .406 \\
\hline
\end{tabular}

De zuivere opbrengst der belasting over deze hoeveelheden heaft bedragen in de genoemde jaren :

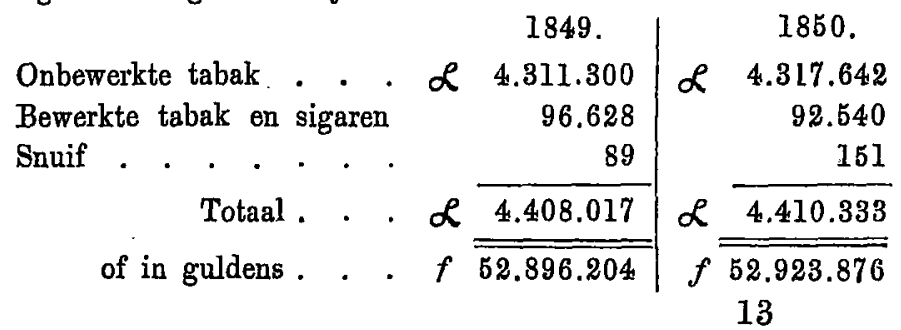


Deze regten bij den invoer zijn het voorname middel waardoor in Engeland het verbruik van tabak wordt getroffen; en ten einde dit te kunnen bewerkstelligen, is dan ook de inlandsche tabak-kultuur aan gestrenge bepalingen onderworpen.

Doch behalve deze regten bij den invoer, wordt de tabak-consumtie nog getroffen door eene belasting op de inlandsche tabakhandelaars en verwerkers van tabak. - Deze zijn verpligt tot uitoefening van hun bedrijf een soort van patent te nemen (licence) waarvan de opbrengst onder het middel der accijnsen wordt gerekend. - - Deze opbrengst komt echter in geene vergelijking met die der invoerregten.

De volgende staat $\left(^{*}\right)$ geeft hieromtrent een overzigt:

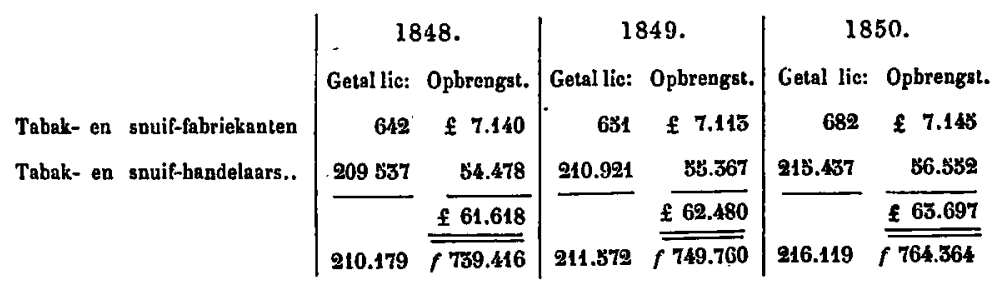

Hieruit schijnt dus op te maken, dat er in de laatste jaren eene doorgaande toeneming in het verbruik bestaat, hetgeen ook overeenkomt met een overzigt ran het totaal verbruik in den laatsten tijd.

Invoer tot verbruik in Groot-Brittanje en Ierland.

Kilog.

$$
\begin{aligned}
& 1842-10.109 .000 \\
& 1843-10.460 .000 \\
& 1844-11.179 .000 \\
& 1845-11.892 .000 \\
& 1846-12.208 .000 \\
& 1847-12.108 .000 \\
& 1848-12.360 .000 \\
& 1849-12.524 .000 \\
& 1850-12.540 .000
\end{aligned}
$$

De opbrengst der tabak-belasting is thans nagenoeg het vierdubbel van hetgèen zij was in het begin dezer eeuw.

De volgende cijfers ontleenen wij aan het bekende werk van Pon'sen, Progress of the Nation:

(*) Tables of the Revenue, Population, etc. 1852 png. 33. 


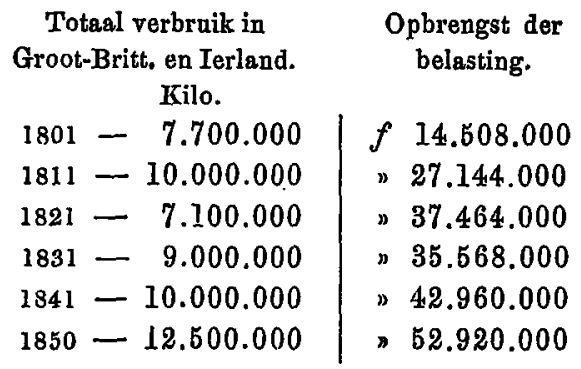

Deze vermeerderde opbrengst is verkregen door eene trapsgewijze verhooging der tarieven, welke dan ook de' tabak-consumtie, berekend per hoofd der bevolking, over het geheele Vereenigde Koningrijk, eene ligte vermindering heeft doen ondergaan, in vergelijking met het begin der eeuw. - Doch die vermindering in het verbruik per hoofd is bijna nitsluitend veroorzaakt door het verminderd verbruik in Ierland. In Engeland en Schotland is de consumtie per hoofd nagenoeg dezelfde gebleven, niettegenstaande de telkens hooger regten; zoodat de tariefs-verhooging aldaar ook nagenoeg eene evenredige vermeerdering der opbrengst heeft medegevoerd.

\section{Engetand en Schotland.}

Tarief der bel: Verbruik. Verbr. p.hoofd.

\begin{tabular}{cc|c|c} 
& & \multicolumn{1}{c}{ Kilo. } & Krilo. \\
$1801-f 2.10$ & per kil. & 4.770 .000 & 0,430 \\
$1811-2.90 "$ & 6.800 .000 & 0,520 \\
$1821-5.30 "$ & 5.900 .000 & 0,404 \\
$1831-4 .-$ & & 7.000 .000 & 0,415 \\
$1841-4 .-$ & & 7.600 .000 & 0,408
\end{tabular}

In Ierland was dit niet het geval, zooals hieronder wordt aangetoond:

\section{Ierland.}

Tarief der bel.

Verbruik. Verbr. p. hoofd.

Kilo. Kilo.

\begin{tabular}{ll|l|l}
$1801-f 1.32$ per kilo & 2.900 .000 & 0,632 \\
$1811-2.11$ & v & 2.930 .000 & 0,485 \\
$1821-4 .-$ & & 1.200 .000 & 0,172 \\
$1831-4 .-$ & & 1.900 .000 & 0,240 \\
$1841-4 .-$ & & 2.500 .000 & 0,300
\end{tabular}

Men ziet dus dat de verdubbelde belasting ( $\operatorname{van} f 2.10$ tot $f$ 4) voor Ierland eene aanzienlijke vermindering in de consumtie ten gevolge 
had - en dat het gemiddeld verbruik per hoofd thans nagenoeg de helft is van het verbruik in het begin der eeuw - terwijl het verbruik per hoofd in Engeland thans weer nagenoeg hetzelfde is als vroeger.

Men bedenke echter hierbij, dat er voortdurend een zeker bedrag door den sluikhandel wordt aangebragt, hetwelk alzoo niet onder de officieele consamtie wordt geteld: welk bedrag waarschijnlijk grooter is, naarmate de tarieven hooger zijn; zoodat dan ook hier het wezenlijk verbruik aanzienlijker is dan door de tabellen wordt aangetoond.

De hoeveelheid tabak welke door den sluikhandel wordt ingevoerd, kan natuurlijkerwijze niet met juistheid worden opgegeven. - Die hoeveelheid wordt echter door verschillende bevoegde beoordeelaars in Engeland, (zoowel handelaars als anderen), gerekend, ongeveer even groot te zijn als het bedrag dat op wettige wijze in verbruik wordt gebragt, - zoodat de geheele tabakconsumtie volgens hunne meening, op 55 millioen Eng. Pond, of ongeveer 25 millioen Kilo moet gesteld worden.

Deze meening omtrent den waren stand der zaken vindt te meer grond, indien men nagaat:

$1^{0}$. dat bewerkte tabak op velerlei plaatsen te verkxijgen is tegen den prijs van $f 2$ à $f 2.70$ het Kilo (1 sh. 6 p. ̀̀ 2 sh. het Eng. terwijl de belasting alleen p. m. $f \&$ per Kilo bedraagt.

$2^{0}$. dat meermalen pogingen zijn angewend om de tabak-handelaars in het algemeen aan te sporen tot het petitioneren voor eene vermindering der regten; waartoe men echter nimmer meer dan eenige enkelen uit den tabakhandel heeft kunnen vereenigen; het getal van hen die deze beweging, openlijk of heimelijk, tegenwerkten, was altijd grooter dan het getal der medewerkenden, $\left(^{*}\right)$ een duidelijk bewijs dat de meerderheid voordeel vond in de hooge regten. -

Deze feiten te zamen genomen kunnen wederom strekken om het nadeel van overdreven belasting te betoogen; - en de bedenking doet zich voor, dat het ook hier welligt mogelijk zou zijn, om door een aanzienlijke vermindering der regten, tegelijk de zedelijkheid te bevorderen, door het tegengaan van den sluikhandel: - de ingezetenen te bevoordeelen, - en tevens de winsten voor de schatkist te blijven behouden, of welligt te vermeerderen. Eene belasting die gemiddeld vijf à zes maal de volle waarde der grondstof

(*) Financial Reform tracts. The Cost of Customs and excise dnties; by the Liverpool financial reform association. - Price sixpence. 
bedragt, mag gerust overdreven genoemd worden - en daar heeft men dan ook spoedig de grenzen van profitable taxation overtreden, met andere woorden: "de schatkist verliest alsdan meer door het smokkelen en het verminderd verbruik, dan zij door het hooger tarief bevoordeeld wordt.

Doch welke fouten er ook aan de Engelsche tabak-belasting mogen aankleven, zeker is het dat de voordeelen voor de algemeene inkomsten ook sterk sprekende zijn; en daarom wilden wij de aandacht onzer lezers een oogenblik op dit onderwerp vestigen.

Want, al erkent men de menigvuldige zwarigheden die er aan verbonden zijn, - alle partijen zullen dit toestemmen, dat weinig zaken zich zoozeer als voorwerp ran belasting anbevelen, als de tabak. - Daarvan bestaat een uitgebreid verbruik, en dat verbruik is geheel improductief. - Eene vermindering van dat verbruik bevoordeelt de productie in plaats van haar te benadeelen. Het onderwerp is dus de aandacht van allen die zich met rolkswelvaart bezig houden, overwaardig. Daarom wordt hier op eenige officiele cijfers verwezen, om door de praktijk te doen zien, wat eene tabakbelasting zijn kan. -

RED. 